\title{
SPANISH AMERICA COMO O OUTRO DA AMÉRICA
}

\section{JOÃO FERES JÚNIOR}

O homem comum toma a idéia de caráter nacional de maneira extrema; e, uma vez tendo estabelecido como princípio que algum povo é dissimulado, covarde e ignorante, ele não admite exceção, e imputa sobre todo e qualquer indivíduo daquele povo as mesmas pechas. (David Hume, Of National Characters)

Nós, habitantes do presente, às vezes nos surpreendemos com as descontinuidades reveladas pelo estudo do passado. Por exemplo, o termo "América Latina", e suas respectivas traduções, hoje frequienta com assiduidade as páginas dos jornais, os textos dos intelectuais e acadêmicos, e os discursos dos homens públicos e dos cidadãos comuns em todo o mundo. Muitas pessoas utilizam-no mas poucos sabem que ele é na verdade uma invenção conceitual razoavelmente recente. Apesar do debate acadêmico a respeito de sua primeira aparição e autoria, podemos afirmar, até que se ofereçam evidências em contrário, que o termo foi usado pela primeira vez em 1856 no poema Las dos Américas (1856) de José Maria Torres de Caicedo - um jornalista, poeta, crítico e escritor colombiano que viveu em Paris por quase toda sua vida adulta (Ardao 1980; Vargas 1989).

Enquanto que América Latina em espanhol e a forma francesa Amérique Latine começaram a ser usadas já a partir de meados do século XIX, a tradução inglesa, Latin America, só apareceu na última década daquele século, como informa o Oxford English Dictionary. ${ }^{2} \mathrm{O}$ mesmo dicionário conta que antes do aparecimento de Latin America, Spanish America era a expressão mais utilizada pelos falantes da língua inglesa ao se referirem aos habitantes das ex-colônias de Espanha e Portugal no Novo Mundo.

O presente texto é parte de um trabalho mais amplo de estudo da história do conceito de Latin America nos Estados Unidos, que envolve o exame dos conteúdos semânticos atribuídos ao termo tanto no uso do inglês comum quando nos discursos especializados sobre Latin America formulados por cientistas sociais daquele país. Nossa análise dos usos de "Latin America" no âmbito da linguagem comum, que cobre quase todo o século XX, identificou a presença recorrente de três tipos de oposições assimétricas no campo semântico do conceito. ${ }^{3}$ A primeira chamamos de oposição assimétrica cultural, que ocorre quando Latin America é definida pela falta ou negação dos hábitos, costumes e instituições atribuídos ao Eu coletivo Americano. Através dela a America se imagina protestante, universalista e democrática, enquanto que imagina a Latin America, como um Outro católico, particularista e autoritário. A oposição assimétrica temporal, a segunda, ocorre quando Latin America é definida pela falta de sincronia com o presente histórico do Eu coletivo Americano, isto é, por uma incapacidade histórica propriamente dita. Isto é, enquanto a auto-imagem Americana se propõe moderna, progressista e desenvolvida, em uma palavra, como agente de sua própria história, a Latin America é definida como primitiva, tradicional, atrasada ou subdesenvolvida. Por fim, temos a oposição assimétrica racial que ocorre quando o Outro é definido pela falta ou incompletude das características físicas e/ou psicológicas atribuídas ao Eu. No caso em questão, a América se define como branca e anglo-saxã, enquanto que a Latin America é representada pelo nãobranco e mestiço.

Resta-nos saber, contudo, se essas modalidades de oposição assimétrica já estavam presentes no conceito que precedeu historicamente Latin America: Spanish America. O objetivo desse artigo é examinar a história semântica do conceito de Spanish America nos EUA do século XIX, em busca da resposta para essa questão. Através dessa investigação poderemos também observar se houve continuidade semântica entre esses dois conceitos, isto é, se os conteúdos que observamos em Latin America foram de alguma maneira herdados do conceito predecessor.

A exposição do argumento se dará da seguinte forma. Primeiro, explicaremos a tipologia de oposições assimétricas esboçada acima, que derivamos da noção de contraconceito assimétrico elaborada por Reinhart Koselleck, para depois traçarmos a evolução histórica dos discursos sobre Spanish America nos EUA do século XIX, prestando, ao mesmo tempo, atenção ao contexto político em que esses discursos foram formulados e às expectativas e ações por eles autorizadas. Como fonte 
primária utilizaremos trechos de declarações e escritos de políticos, funcionários de governo, jornalistas e intelectuais americanos que de alguma maneira fizeram públicas suas opiniões sobre seus vizinhos continentais.

Reinhart Koselleck é sem dúvida alguma o autor mais influente da história dos conceitos, com uma vasta produção que inclui contribuições importantes à metodologia da disciplina e estudos substantivos da história de conceitos específicos. Entre seus trabalhos mais importantes está a volumosa Geschichtliche Grundbegriffe (1972-1997) — uma publicação de oito volumes com mais de onze mil páginas divididas em 115 ensaios que tratam dos principais conceitos sociais e políticos do período da modernização alemã - para a qual contribuiu como editor geral e autor de vários verbetes.'

Tanto o trabalho metodológico de Koselleck como suas contribuições substantivas tratam em sua maioria de conceitos-chave (Grundbegriffe), ou seja, daqueles conceitos que em um determinado momento histórico se tornam cruciais ao debate político dentro de uma sociedade. Contudo, o mesmo Koselleck escreveu um texto muito interessante sobre uma classe de conceitos políticos de natureza distinta: os contraconceitos assimétricos. ${ }^{6}$ Segundo o autor, contraconceitos assimétricos ocorrem em pares, sendo que um elemento do par é usado por um grupo político ou social para sua auto-identificação coletiva, enquanto que o outro serve para atribuir conteúdos pejorativos àqueles percebidos como estranhos ao grupo - conteúdos esses que são projeções invertidas das qualidades que o grupo se atribui. Koselleck também nota que os contraconceitos assimétricos servem para negar ao Outro a "reciprocidade do reconhecimento mútuo" (1985b, 160). Isto é, enquanto o Eu coletivo afirma sua identidade através desse exercício de (contra)conceituação, o Outro não se reconhece nas qualificações que lhe são atribuídas, ou se o faz, assume necessariamente uma posição de inferioridade.

O primeiro par histórico de contraconceitos estudado por Koselleck é Hellenos/barbaros na Grécia clássica. Os bárbaros não eram simplesmente considerados não-gregos ou estrangeiros, mas, enquanto estrangeiros, eram de fato definidos negativamente como covardes, grosseiros, glutões, brutos etc. O nome de um povo - Hellenos - torna-se o contraconceito para todos os outros, que são agrupados sob um nome coletivo que significa somente o contrário de "Hellenos". Assimetria é, portanto, semanticamente, baseada no contraste consciente de um nome específico com uma classificação genérica (Koselleck 1985a, 166).

Koselleck emprega a noção de horizonte de expectativas para denotar os efeitos cognitivos abertos pelo uso desses conceitos. Para ele, o caráter negativo do campo semântico que define o Outro predispõe o Eu a interpretar evidências empíricas como sinais que confirmam seus "preconceitos". No caso do bárbaro na Grécia, o "contato com comerciantes estrangeiros, a massa de escravos, a devastação dos campos gregos promovida pelos invasores persas e experiências similares podiam ser generalizados facilmente de maneira acrítica" (Koselleck 1985a, 166). Dessa maneira, o bárbaro podia ser apresentado e representado como o Outro absoluto - uma negação total e geral do Eu grego coletivo.

Se prestarmos atenção aos conteúdos semânticos presentes na caracterização que o grego fazia do bárbaro, notamos a dominância da descrição pejorativa de seu modo de vida: usos, costumes, religião, instituições políticas, etc. É importante notar que a semântica de barbaros não tinha espaço para a expectativa de redenção futura das gentes que levavam essa alcunha. Soluções como a conquista das cidades dos bárbaros e sua sujeição a déspotas gregos, ou a escravização de populações bárbaras, não tinham o objetivo de emancipá-los de sua condição supostamente inferior, mas somente de colocá-los, como diria Aristóteles, em sua condição natural (1958). Em suma, no exemplo histórico do par de contraconceitos assimétrico Hellenos/barbaros as oposições semânticas assimétricas (racional/irracional, livre/escravo, político/despótico, etc) não estavam abertas para a possibilidade de transformação histórica. $\mathrm{Na}$ verdade, era exatamente o caráter permanente da condição do bárbaro que garantia, no plano da justificação, um fluxo contínuo de trabalho escravo, e, conseqüentemente, o funcionamento do mundo grego clássico. 
No mesmo texto, Koselleck também examina o par cristão/pagão, que historicamente sucedeu o par Hellenos/barbaros sem contudo substituí-lo completamente. De maneira análoga ao caso anterior, o pagão também era definido pela negação daquilo que constituía ser cristão, e essa definição se referia principalmente ao modo de via desse Outro da cristandade, ainda que esse rótulo tenha sido aplicado a uma variada gama de povos. Contudo, a semântica desse novo par continha um elemento que não estava presente no par Hellenos/barbaros. Desde sua inauguração sob a égide do universalismo de São Paulo, o cristianismo se abriu à conversão dos pagãos, projetando assim um futuro, um horizonte de expectativas, em que o mundo seria inteiramente cristão. Segundo Koselleck, essa idéia, muito cara à doutrina cristã, serviu para justificar do evangelismo militante às conversões forçadas, guerras, saques e massacres dos povos que recebiam a alcunha de pagãos. Acima de tudo, importa-nos ressaltar em relação a esse novo par a inclusão da temporalidade na operação semântica de definição assimétrica do Outro.

Por fim, Koselleck analisa o par Ariano/não-ariano no contexto do nacional-socialismo alemão. Assim como nos casos anteriores, esse par se articula em parte através da inferiorizarão do modo de vida do Outro. Contudo, a definição desse Outro não se dá somente através de conteúdos relativos ao modo de vida, mas também por intermédio da noção de raça - que é irredutível aos termos que descrevem o modo de vida, e, portanto, constitui uma inovação semântica em relação aos pares anteriores. Assim como na díade Hellenos/barbaros, nesse novo par o campo semântico não está aberto à conversão do Outro. Contudo, ao contrário do exemplo antigo, ao qual faltava propriamente uma perspectiva temporal, o par Ariano/não-ariano projeta um horizonte de expectativas que aponta para a eliminação física do Outro, ou, para o controle estrito de sua população e processos reprodutivos.

Pensamos ser possível propor uma tipologia de oposições assimétricas baseada nos apontamentos de Koselleck sobre a estrutura e história dos pares de contraconceitos assimétricos. Ao nosso ver, é possível identificar regularidades nos campos semânticos dos pares contraconceituais que são mais profundas do que aquelas anotadas pelo autor, e por conseguinte, também válidas para pares de contraconceitos diferentes daqueles estudados por ele. Essa tipologia é composta de três formas distintas de oposição assimétrica: cultural, temporal e racial.

A oposição assimétrica cultural corresponde à definição do Outro que se baseia exclusivamente em aspectos do seu modo de vida, ou seja, o Outro é definido pela falta ou negação dos hábitos, costumes e instituições atribuídos ao Eu coletivo. Esse tipo de assimetria corresponde quase que perfeitamente ao exemplo histórico do par Hellenos/barbaros.

Na oposição assimétrica temporal o Outro é definido pela falta de sincronia com o presente histórico do Eu, ou por uma incapacidade de ser agente de sua própria história. O termos associados a esse tipo de oposição assimétrica são retardado, primitivo, atrasado, subdesenvolvido, infantil, senil, entre outros. As raízes dessa percepção temporal se estendem até o cristianismo, contudo sua maturação só se deu com a secularização da expectativa cristã de conversão futura do pagão - coisa que Koselleck poderia ter notado caso sua análise não ficasse restrita ao exemplo histórico do cristianismo primitivo. Historicamente, essa secularização se deu através da temporalização de categorias etnológicas, o que possibilitou que a diversidade das formas de viver dos homens pudesse ser interpretada como estágios de desenvolvimento em uma escala evolutiva. Entre os pioneiros dessa inovação etnológica temos os padres Bartolomé de las Casas e José de Acosta, os quais, no contextos dos encontros do Novo Mundo, usaram do artifício da temporalização para explicar a diferença e, ao mesmo tempo, a humanidade de seus habitantes, criando assim a noção de história universal (Pagden 1982). No século das luzes a história universal se torna ainda mais secularizada com a adoção do progresso material e moral como medida para a classificação temporal dos grupos humanos (ver Condorcet (1795)1988). Desde então, a oposição assimétrica temporal se expressa pela definição do Outro como um prisioneiro do tempo histórico passado, ou, como bem exprimiu o antropólogo holandês Christian Fabian, como sofrendo de "falta de contemporaneidade" (1983).

O terceiro tipo de oposição assimétrica, a racial, ocorre quando o Outro é definido pela falta ou incompletude das características físicas e/ou psicológicas atribuídas ao Eu. Como no caso da oposição assimétrica temporal, a de tipo racial é derivada do texto de Koselleck de maneira muito indireta. Vale notar aqui que esse tipo de oposição se diferencia das outras duas pelo fato de não poder ser reduzida a nenhuma delas, ou mesmo a uma combinação das duas. Raça é, de fato, uma 
construção sócio-cultural, porém, é necessário notarmos que no plano da semântica da linguagem comum essa categoria exprime um conjunto de características físicas e psicológicas que se colocam além (ou aquém) da cultura e do tempo.

Uma vez definida nossa tipologia das formas de oposição assimétrica, passaremos agora à análise do conceito de Spanish America nos EUA do século XIX.

\section{II}

Referências pejorativas às coisas espanholas eram comuns na língua inglesa muito antes da incorporação do conceito de Latin America. As disputas religiosas do século XVI, assim como o terror inspirado pelo poderio da Armada Espanhola contribuíram para a consolidação de um sentimento anti-espanhol forte por parte dos habitantes da Grã-Bretanha, e de outros povos europeus que em algum momento de sua história estiveram sob o poderio da coroa espanhola. Esse sentimento foi batizado de Legenda Negra. Expressões claras da Legenda Negra podem ser encontradas na literatura ficcional britânica, em tratados políticos, jornais e panfletos, discursos de políticos, militares e intelectuais.' Um dos temas mais correntes da Legenda Negra são os maus-tratos e crueldades perpetradas pelos colonizadores espanhóis no Novo Mundo contra os nativos. Não raro a descrição dos supostos horrores da colonização espanhola servia de instrumento retórico para, por comparação, elogiar a "ordem" e "justiça" da colonização inglesa.

A Legenda Negra cruzou o Atlântico com as levas de colonizadores ingleses. Conseqüentemente, o sentimento anti-espanhol foi estendido de seu objeto original, a Espanha européia, às colônias espanholas do Novo Mundo. ${ }^{9}$ Por exemplo, o segundo presidente dos EUA, John Adams, escreveu a Thomas Jefferson:

... um governo livre e a religião católica romana não poderão jamais coexistir, em qualquer país ou nação. Consequientemente, qualquer projeto de conciliar essas duas coisas na velha ou na nova Espanha é utópico, platônico e quimérico. A prostração e prostituição da natureza humana aos clérigos, que presenciei na velha Espanha, são tamanhas, que formaram minha opinião sobre o assunto, há muito tempo. E é de meu entendimento que na Nova Espanha as coisas são ainda piores, se isso é possível. (Cappon 1988, 571)

Fiel aos sentimentos anti-espanhóis de seu pai, John Quincy Adams, o quinto presidente dos EUA, escreveu em seu diário a seguinte passagem, quando, ainda jovem, visitou o norte da Espanha:

[Os espanhóis] são vadios, sujos e malvados, em suma, seria justo compará-los a uma vara de porcos. (Taylor and Friedlaender 1981, 17-27)

Como o pai, John Quincy Adams também estendeu suas opiniões negativas das coisas espanholas para a "Nova Espanha", continuando a professá-las na vida adulta, mesmo depois de as colônias espanholas terem conquistado sua independência através de movimentos de libertação com forte cunho republicano. Em uma carta a Henry Clay, Quincy Adams escreveu:

[Spanish Americans] não possuem sequer os mais básicos elementos de um governo livre. A desordem civil está impregnada em seus princípios mais básicos. A guerra e a destruição mútua habitam cada membro de sua organização, moral, política e física (Adams and Adams 1970, 5:325)

Coerente em sua visão, Quincy Adams se opôs ao reconhecimento oficial de sua emancipação política por parte dos EUA.

Adams pai e filho não estavam sozinhos no que tocava os sentimentos anti-espanhóis nos EUA. Ao comentar os prospectos das novas repúblicas da América espanhola, Thomas Jefferson declarou: 
A história não conhece exemplo de um povo dominado por padres que tenha constituído um governo livre. (Jefferson e Ford 1904, 13:40)

Um representante do governo americano mandado para a Venezuela em 1812, Alexander Scott, relatou ao presidente James Monroe que o povo daquele país era "tímido, indolente, ignorante, supersticioso, incapaz de se esforçar e desprovido de iniciativa" (Scott 1812). O representante na Colômbia, Beaufort Watts, foi mais além, escrevendo em 1828 que o típico colombiano era "um animal obediente que se torna ainda mais submisso e dócil quando castigado" (Watts 1828).

Devemos notar que essas primeiras manifestações de desprezo pelos hispano-americanos já eram construídas na forma de oposições assimétricas. Cada uma das características negativas atribuídas a eles, isto é, dominados por curas (católico), indolentes, ignorantes, supersticiosos, incapazes de se esforçar e desprovidos de iniciativa - corresponde a características positivas da autoimagem americana protestante (portanto anti-católico), trabalhador, educado, racional, industrioso e provido de espírito de iniciativa. Dado que esses adjetivos pejorativos descrevem estilos de vida, hábitos e costumes, podemos afirmar que se encaixam dentro da categoria de oposições culturais assimétricas.

As expectativas associadas a essas oposições eram muito pessimistas. Para John Adams, o catolicismo e o governo livre são irreconciliáveis, ou seja, enquanto a América espanhola continuar católica, ela não gozaria de tal governo. Thomas Jefferson é de opinião semelhante. Já John Quincy Adams leva as oposições culturais assimétricas um passo adiante, abrindo a possibilidade de traduções raciais. Primeiro, ao comparar os espanhóis a animais, mais especificamente, porcos, sugerindo que sua vileza é tão aguda a ponto de desumanizá-los, e segundo, ao dizer que "a guerra e a destruição" estão impregnados não só em suas instituições morais e políticas, mas também em sua constituição física. Beaufort Watts também se aproxima de Quincy Adams, ao comparar o "típico colombiano" a um cão subserviente.

A introdução de elementos raciais modifica o horizonte de expectativas projetado sobre os hispano-americanos, em inglês. Enquanto seus hábitos culturais "deploráveis" são atribuídos ao catolicismo, a possibilidade de solução através da reforma cultural estará sempre aberta. Contudo, quando maus hábitos são atribuídos à inferioridade racial, esta possibilidade se fecha. Nesse caso, resta somente as medidas que possam controlar e manipular seus corpos, exemplo: segregação, controle reprodutivo, deportação, controles migratórios e extermínio. Devemos notar que no conjunto de citações apresentado acima, há somente alusões indiretas à raça, enquanto que as oposições culturais assimétricas preponderam explicitamente.

Mesmo que possamos constatar expectativas pessimistas nos discursos de alguns representantes do governo americano do início do século XIX, elas não chegaram a produzir uma política externa consistente à época. Os EUA, então uma nação jovem e agrícola, quase não tinha contatos com os países do sul. Contudo, na primeira manifestação importante de política externa americana que dizia respeito à América Espanhola, a declaração do presidente James Monroe (mais tarde batizada de Doutrina Monroe), os EUA trataram seus vizinhos de maneira altamente assimétrica, arrogando-se em defensores do continente e deixando de reconhecer a autonomia das repúblicas na defesa de seu próprio território. ${ }^{10}$ Esse procedimento foi coerente com as expectativas projetadas a partir do campo semântico do conceito de Spanish America nos EUA do início do século XIX.

A situação de isolamento dos EUA em relação a seus vizinhos continentais começou a se alterar no segundo quarto do século XIX, com o florescimento de projetos expansionistas naquele país. A expansão de fato foi iniciada em 1819, com a aquisição da Flórida, vendida por um valor quase simbólico aos EUA pela Espanha, por receio de uma invasão americana iminente (Schoultz 1998). Mas o debate expansionista só recrudesceu com a anexação do Texas e, posteriormente, com o advento da guerra contra o México.

Com o fim do isolamento continental americano, os discursos a respeito dos hispanoamericanos assumiram novas colorações. Por exemplo, ao comentar, em 1843, a campanha vitoriosa dos colonos brancos do Texas contra o estado Mexicano, o Secretário de Estado dos EUA, Abel Upshur declarou: 
Nenhum homem que conhece minimamente sua própria natureza supõe ser possível que duas raças de homens, distintas por marcas externas indeléveis e perceptíveis a olho nu, que mantiveram desde tempos imemoriais uma relação de senhor e escravo, possam algum dia viver juntas, como iguais, no mesmo país, sob o mesmo governo. (Upshur 1843)

O Texas foi finalmente anexado à união federativa americana em 1845. Em menos de um ano, os EUA iniciariam uma guerra contra o México.

A escalada do conflito deu-se da seguinte maneira. O então presidente americano, James K. Polk mandou um emissário secreto, John Slidell, ao México, com a susposta tarefa de cobrar do governo mexicano indenizações decorrentes da disputa pelo Texas e de negociar uma questão de disputa de fronteiras. Os mexicanos entendiam que o rio Nueces era a fronteira sul do Texas, e, portanto, agora também a dos EUA, enquanto que os americanos argumentavam que o rio Grande, que corre em média 100 quilometros ao sul do Nueces, correspondia de fato à linha fronteiriça. Slidell tinha, na verdade, um objetivo mais importante: oferecer aos dirigentes daquele país uma proposta de compra dos territórios mexicanos do Novo México e da Califórnia por 30 milhões de dólares. Os mexicanos rejeitaram veementemente essa proposta, assim como negaram-se a reconhecer o rio Grande como limite de fronteira.

Diante da recusa dos mexicanos, Polk ordenou a invasão da área entre os rios. Os mexicanos logo revidaram com um ataque às tropas invasoras. Polk então enviou mensagem ao congresso no dia 11 de maio de 1846 dizendo que o México "havia invadido nosso território e derramado sangue americano em solo americano". Dois dias depois, o Congresso aprovou uma declaração de guerra contra o México com esmagadora maioria, inicando assim formalmente o conflito que iria resultar na anexação por parte dos EUA de 1,3 milhão de quilômetros quadrados de território mexicano - uma área que correspondia aproximadamente à metade do território daquele país e onde hoje estão os estados americanos da Califórnia, Novo México, Utah, Nevada, Arizona e Colorado.

A maioria congressual que apoiou a guerra não voltou a se formar nos debates a respeito da anexação dos territórios. Enquanto que os democratas do sul viam na expansão uma oportunidade para aumentar o número de estados escravocratas e, portanto, seu poder político na União, os Whigs e os abolicionistas do Norte se opunham a ela. O que nos interessa aqui não é exatamente sua posição sobre a expansão em si, mas os argumentos usados para referendá-la ou rejeitá-la. Por exemplo, ao discutir em 1847 no Congresso o assunto da anexação, o senador John Berrien perguntou à sua audiência:

Vocês intencionam colocar seus direitos sagrados (birthright) nas mãos das raças de mestiços (mongrel) que habitam esses territórios?" Pois é isso que se dará caso eles sejam incorporados à nossa União (Berrien 1847).

Também contrário à anexação dos territórios, o deputado do estado de Nova Iorque, Washington Hunt obtemperou:

[...] pensem no caráter da população que virá com eles [os territórios] para dentro de nossa Confederação. Devemos nos preparar para receber uma massa incôngrua de espanhóis, índios e mexicanos mestiços (mongrel) - uma mescla de raças misturadas ${ }^{12}$ que não podem administrara ou sequer gozar de nossas instituições livres: homens de sangue e língua diferentes, que não podem se misturar ao nosso povo em pé de igualdade social e política.

Mas Hunt se permitiu conceber uma provável incorporação dos territórios, contudo, fazendo a seguintes ressalvas:

[...] eles devem ser governados como uma dependência colonial, sob leis especiais, caso contrário, se incorporados ao nosso sistema federal, tornar-se-ão uma fonte eterna de baderna, anarquia e comoção social. (Hunt 1847) 
Enquanto que nas citações do início do século a questão da raça aparecia somente de maneira alusiva, durante a Guerra Mexicana ela tornou-se o principal instrumento retórico para se afirmar a inferioridade dos mexicanos e dos hispano-americanos em geral. Uma análise mais cuidadosa das falas dos políticos acima mostra que as características raciais atribuídas por eles aos mexicanos carecem de especificidade. Eles são chamados de massa incôngrua de espanhóis, índios e mexicanos mestiços, e mescla de raças misturadas. Ou seja, sua característica racial mais marcante é não serem brancos - fato sugerido na referência que Hunt faz à diferença de sangue. Ademais, o argumento apresentado por Upshur de que essas duas raças de homens "mantiveram desde tempos imemoriais uma relação de senhor e escravo" só pode ser entendido como uma referência ao fato de que, por terem a pele escura, os habitantes nativos do Texas pertencem à mesma categoria de homens escravizados pelo homem branco desde tempos imemoriais: os negros. Não obstante a falácia histórica de tal afirmação, devemos notar que ela é estruturada em torno de uma oposição racial assimétrica. Enquanto o Eu identifica-se como branco, ele projeta sobre o Outro uma categoria genérica e abrangente de não-branco, que se estende de maneira indistinta a mestiços, índios, espanhóis e negros.

Como indicado nas citações acima, com o expansionismo as expectativas dos americanos a respeito dos hispano-americanos se transformaram, de manifestações de desdém ocasionais e esparsas, em uma questão política candente. Como afirma Reginald Horsman, o debate substantivo à época "não era sobre território, mas sobre os mexicanos"(1981), observação que se confirma através da leitura das passagens acima. A percepção de inferioridade racial abria um leque limitado de alternativas para o futuro. Por exemplo, mesmo opondo a anexação plena, Hunt quer que os territórios sejam administrados como colônias, sob leis especiais. Se comparada à solução que foi de fato dada à questão, a proposta de Hunt parece até amena. Os territórios foram incorporados à União e mais tarde tornaram-se estados da federação; porém, a maioria da população nativa nunca chegou a ser plenamente emancipada. Grande parte dos índios foi dizimada por colonizadores e pelo exército americano, e os índios e mestizos que restaram no território sofreram por décadas um processo de segregação social e legal similar ao sistema Jim Crow do Sul dos EUA (Camarillo 1990; Bender 2003).

Os mexicanos não foram o alvo exclusivo dessa modalidade de discurso racial americano. Tal percepção negativa era também estendida à América Espanhola em geral, como ficou registrado na seguinte passagem do senador da Carolina do Sul, John Calhoun ${ }^{13}$ :

Nunca sonhamos incorporar à nossa União qualquer raça senão a caucasiana - a raça branca livre. Incorporar o México seria algo como incorporar uma raça de índios, pois metade dos mexicanos são índios e o resto é composto de tribos mestiças ${ }^{14}$. Eu veementemente protesto contra essa união! O nosso, meu senhor, é o governo da raça branca. As maiores desgraças da América Espanhola advém do erro fatal de terem colocado essas raças escuras ${ }^{15}$ em pé de igualdade com a raça branca. (Calhoun 1848)

Nessa passagem, Calhoun usa o México como um exemplo particular de uma totalidade mais geral: a América Espanhola. Há traços aqui de um raciocínio sinedóquico, de se estender a percepção do México ao resto do subcontinente. Também pode-se notar a oposição assimétrica racial na comparação entre a "raça branca livre" e as outras raças "escuras" e "misturadas", que por inferência devem ser consideradas servis. Na passagem acima, Calhoun não dá qualquer relevância à independência das repúblicas, que na época tinham cerca de trinta anos de existência, preferindo atribuir as "desgraças da América Espanhola" ao "erro" da mistura racial. A inferiorização racial do outro serve de base para dois tipos de expectativas: condenar a história da América espanhola ao eterno fracasso e rechaçar qualquer projeto futuro de incorporação de povos marcados pela mistura racial à união americana.

Foi também durante a guerra contra o México que a variante mais radical do nacionalismo americano consolidou-se: a doutrina do Destino Manifesto. Os elementos mais marcantes dessa doutrina podem ser vistos em operação na seguinte passagem de autoria de Ralph Waldo Emerson ${ }^{16}$ : 
Certamente, a forte raça britânica, que já conquistou grande parte desse território, deve também apoderar-se daquele pedaço [Texas], e do México e do Oregon também; e, com o passar das eras, os métodos e situações segundo os quais isso foi feito será de pouca importância. Pois esta é uma questão secular [...]

A América é o último esforço da Divina Providência em favor da raça humana, um novo começo de uma civilização nova e mais avançada [...] a casa do homem, que deve se estender às ondas do Oceano Pacífico. Um Destino amigável e sublime."

Segundo o argumento de Emerson, a superioridade racial americana está amparada por um poder ainda mais alto: a vontade de Deus, a Divina Providência - frente a qual as "questões seculares" perdem importância. O recurso à vontade divina justifica o relativismo moral adotado pelo autor em relação aos crimes da conquista e da ocupação dos novos territórios. No fim das contas, o que importa é o triunfo da raça britânica dos EUA e não as razões e justificativas usadas para se alcançar esse triunfo.

A expressão Destino Manifesto foi articulada pela primeira vez pelo jornalista e agitador político John O’Sullivan, um defensor obstinado do expansionismo americano. Na visão do autor:

O Texas foi absorvido pela União no processo inevitável de cumprimento da lei geral que está levando nossa população em direção ao oeste [...] Ele foi arrancado do México de acordo com o curso natural dos eventos, por um processo, em si, perfeitamente legítimo, do qual não temos nenhuma culpa, e no qual todas as censuras resultantes dos malefícios, da perfídia e da loucura recaem somente sobre o México. [...]

O braço avançado do irresistível exército da emigração Anglo-saxã já começou a se estender sobre a Califórnia, armado com o arado e o rifle, a deixando ao longo de seu caminho escolas e faculdades, tribunais e câmaras legislativas, moinhos e casas de reunião. $^{18}$

De novo, a percepção da diferença racial, ancorada no argumento da vontade Divina, serve para justificar padrões morais distintos, segundo os quais os americanos não poderiam perpetrar o mal através de suas ações, enquanto que os mexicanos pecariam simplesmente por resistir à manifestação secular dessa vontade, que se realiza através da expansão territorial da raça anglo-saxã americana.

A doutrina do destino Manifesto criou raízes no solo da auto-imagem americana. Após encerrada a guerra contra o México, os EUA entraram em um período de disputas internas que culminou com a guerra civil americana (1861-1865). Com a reestruturação política interna que se seguiu à guerra e a retomada do crescimento, agora sob a égide dos industrialistas do nordeste, novos desígnios expansionistas começaram a ser alimentados. O "inimigo" agora era a Espanha monárquica e colonialista. Na guerra rápida que se seguiu ao incidente com o USS Maine, no porto de Havana, Cuba, os EUA derrotaram as forças espanholas e apoderaram-se de suas colônias: Cuba, Porto Rico, Filipinas e a ilha de Guam. Mais uma vez, os americanos defrontaram-se com o problema do que fazer com as "raças indesejáveis" que habitavam os territórios por eles conquistados. Mais uma vez, os indesejáveis eram, de algum modo, percebidos como hispânicos.

O Destino Manifesto ressurgiu com força no debate público que precedeu a guerra e também nas discussões que se seguiram à vitória, como podemos ver abaixo na declaração do historiador e senador pelo estado de Ohio, Albert Beveridge, datada de 1900:

Deus não preparou os povos anglófonos e teutônicos por mil anos para uma contemplação vã e inútil e a auto-admiração. Não! Ele nos fez os mestres organizadores do mundo para estabelecer um sistema onde reina o caos. Ele nos deu o espírito do progresso para sobrepujarmos as forças da reação por toda a terra. Ele nos fez adeptos do bom governo para que possamos administrá-lo aos povos selvagens e senis. Não fosse por tal força, esse mundo se afundaria no barbarismo e nas trevas. E, de toda nossa raça, ele marcou o povo americano como Sua nação escolhida para finalmente liderar no trabalho de regeneração do mundo. Essa é a missão divina da América, e ela reserva a todos nós todo os proventos, 
toda a glória e toda a felicidade possível ao ser humano. Nós somos os depositários do progresso mundial, os guardiões da paz virtuosa. (Beveridge 1900)

O trecho acima contém todas as três formas de oposição assimétrica. Primeiro, encontramos a raça anglófona e teutônica superior contrastada a todos aqueles que não pertencem a ela. Segundo, a oposição assimétrica cultural está presente na identificação do Outro como bárbaro e selvagem - termos que sugerem ser também a raça superior o bastião da civilização. Por fim, o Outro é caracterizado como selvagem ou senil, isto é, como imaturo ou decrépito - imagens carregadas de sentido temporal que denotam sua falta de sincronia com o momento histórico presente. ${ }^{19}$

A doutrina do Destino Manifesto acrescenta um aspecto novo a argumentos puramente racistas, como os usados por Upshur, Berrien e Hunt ao discutirem a questão da anexação de território mexicano. Esse aspecto é a oposição assimétrica temporal. O edifício ideológico dessa doutrina é estruturado ao redor da premissa de que os americanos anglo-saxões são a raça escolhida por Deus para ser o instrumento de Sua vontade na terra. Portanto, segundo essa concepção, a graça divina é o princípio organizador da história humana, e os americanos seus agentes verdadeiros e legítimos.

Nesse caso, a oposição assimétrica racial funciona como um marcador para a assimetria temporal. É através da raça anglo-saxã, identificada como povo escolhido, que a Divina Providência pode se transformar em história humana. Porém, essa transformação não corresponde a uma secularização completa. Se por um lado o drama do expansionismo americano é encenado na terra, por outro, a justificação moral das ações dos americanos é de ordem divina - vide os argumentos de Emerson e O'Sullivan defendendo a absolvição total dos atos dos americanos e a culpa intrínseca dos mexicanos. Ao apelar para o conhecimento privilegiado das coisas divinas, a doutrina do Destino Manifesto é capaz de produzir um cinismo moral poderoso, que dificilmente poderia ser refutado por uma razão prática de ordem secular.

No capítulo anterior nós identificamos, com Koselleck, a presença de oposição assimétrica temporal já na concepção cristã do Outro como pagão, para depois mostrar uma forma historicamente posterior a essa operação semântica articulada pelas teorias iluministas do desenvolvimento secular. No caso da doutrina do Destino Manifesto, a assimetria temporal em operação assemelha-se mais à articulada pela escatologia cristã antiga, pelo menos no que tange à valorização da providência divina como chave para se entender a história humana. Como fica explícito nas referências de O'Sullivan ao arado, rifle, escolas e faculdades, tribunais e câmaras legislativas, moinhos e casas de reunião, os ideólogos do Destino Manifesto às vezes lançavam mão do argumento da superioridade material e moral da raça anglo-saxônica. Contudo, essas coisas eram interpretadas como sinais, ou expressões de uma superioridade que, mediada pelo aspecto da raça, seria divinamente ordenada.

Devido ao seu forte componente temporal, a doutrina do Destino Manifesto é por excelência um discurso sobre expectativas. Do ponto de vista de nosso exercício teórico, ela fornece um exemplo importante de como diferentes formas de oposição assimétrica produzem horizontes de expectativas quando combinados. O elemento temporal redencionista da doutrina parece apontar, como o faz o universalismo cristão primitivo, para um momento futuro de solução da diferença. No caso do Destino Manifesto, a redenção se daria quando todos os homens fossem conduzidos pelos americanos ao ápice do desenvolvimento civilizacional. Alguns dos textos acima sugerem esse desfecho. Contudo, a presença do elemento racial é um obstáculo a esse tipo de solução, pois se a raça é entendida como fator biologicamente transmitido, os povos inferiores nunca alcançariam o estágio civilizacional dos americanos anglo-saxões. Essa tensão entre expectativas conflitantes aponta para soluções como a colonização com segregação racial, imigração controlada visando à diminuição das populações não-brancas, seu controle reprodutivo ou mesmo sua eliminação.

Os trechos acima indicam que com a maturação da doutrina do Destino Manifesto o sentimento anti-espanhol só fez crescer e se sofisticar, adquirindo assim contornos messiânicos. A América Espanhola podia agora ser representada pelas três formas de oposição assimétrica: cultural, racial e temporal. É importante salientar que, mesmo que os fundadores da doutrina tenham se preocupado inicialmente com o México, esse não foi o único alvo dessa forma fortalecida de ideologia anti-espanhola. ${ }^{20}$ Os exemplos de uso de referências igualmente preconceituosas aos povos 
de outras repúblicas hispano-americanas e do Brasil são abundantes. ${ }^{21}$ Por exemplo, o representante do governo dos EUA para a América Central, George Squier, escreveu já em 1849:

Comparados às repúblicas da América Espanhola, os Estados Unidos consolidou um avanço incomensurável em todos os elementos de grandeza. Esse resultado é uma conseqüência eminente da recusa por parte da raça teutônica de poluir seu sangue, turvar seu intelecto, rebaixar seus padrões morais e por em perigo suas instituições com a mistura a raças humanas inferiores e subordinadas. Em obediências aos céus, [a raça teutônica] já salvou metade do continente do domínio de feras selvagens e de homens ainda mais selvagens [...] Somente através de um sistema judicioso de colonização, que deve assegurar a predominância do sangue branco, ao mesmo tempo que introduz inteligência, indústria e habilidade, que a [América Central] pode ter esperança de alcançar paz, prosperidade e grandeza. (Squier 1855, 57-58, 234)

A mesma combinação de oposições assimétricas que foram usadas para tratar o México, são aqui empregadas para fazer-se sentido da América Espanhola. Essa passagem de Squier apresenta todos os elementos da doutrina do Destino Manifesto. Interessa notar que, talvez por ser um funcionário do Estado, Squier aventura-se a transformar suas expectativas em sugestões de políticas concretas. Sua solução para o "problema" da América Espanhola, que ele atribui primordialmente à inferioridade racial de seu povo, consiste na colonização branca e no combate à miscigenação racial. Mesmo que ele não diga explicitamente o que será feito das populações racialmente inferiores que habitam o lugar, podemos assumir que esse sistema colonial perpetraria sua submissão perpétua e o controle de suas atividades reprodutivas, senão eliminação gradual.

O uso de oposições assimétricas para representar os povos ao sul do Rio Grande não era exclusividade de políticos e funcionários do governo dos EUA, intelectuais, acadêmicos e viajantes também partilhavam dessa percepção. Ao comentar a viajem que empreendeu ao Brasil, em 1866, o capitão John Codman deplora a mistura racial na população, e conclui, com uma linguagem rica em oposições temporais e culturais:

[...] deixe que o governo, a aduana, que o correio e os tribunais sejam dirigidos por intelectos norte-americanos, que o solo seja cultivado pela energia e pelas máquinas norteamericanas, e abaixo irão as relíquias decrépitas da barbárie. (Codman 1867)

O famoso naturalista americano Louis Agassiz e sua esposa criticaram veementemente a mistura de raças que viram no Brasil:

Não se pode negar a deterioração causada pela mistura de raças, mais presente aqui do que em qualquer outro lugar do mundo. Ela está ceifando rapidamente as melhores qualidades do homem branco, do negro e do índio, deixando em seu lugar um tipo mestiço (mongrel) sem qualidades específicas, deficiente em suas energias físicas e mentais. (Agassiz and Agassiz 1895)

Assim como Codman, o casal Agassiz estende ao Brasil o diagnóstico negativo produzido a respeito dos hispano-americanos.

Como no caso do México, a descrição pejorativa da América Espanhola foi acompanhada por intervenções e violência por parte dos EUA. Somente no século XIX, os EUA anexaram metade do território do México, patrocinaram oficialmente a pirataria na América Central (as aventuras de William Walker, na Nicarágua, são o exemplo mais lamentável), interferiram em uma guerra entre Chile e Peru e forçaram a arbitragem de uma disputa de fronteiras entre Venezuela e Grã-Bretanha onde os representantes venezuelanos não foram incluídos na mesa de negociação (Smith 1996). Ao fim daquele século, os EUA entraram em guerra contra a Espanha e, como espólio de sua vitória, apropriaram-se de Cuba e Porto Rico. 
Como vimos no texto acima, o conceito de Spanish America serviu de contraconceito para a consolidação da ideologia nacionalista americana no século XIX. Identificamos o processo histórico de alargamento do campo semântico do conceito através da inclusão das oposições assimétricas cultural, racial e temporal, nessa ordem cronológica. Mostramos também que esse tipo de inferiorização sistemática do Outro cria horizontes de expectativas que servem de guia para ações futuras, quando não de justificativa para ações presentes e passadas. Mais especificamente, em relação aos povos identificados em inglês como Spanish American, as ações americanas durante o século XIX se pautaram pela unilateralidade e violência.

O exame da evolução histórica do campo semântico de Spanish America, empreendido aqui, serve para formularmos questões e hipóteses sobre os significados atribuídos ao conceito de Latin America, que a partir do século XX praticamente substitui o termo Spanish America no inglês americano. Será que Latin America "herdou" os três tipos de oposição assimétrica? Poderiam as políticas do governo dos EUA em relação a Latin America, implantadas durante o século XX, ser justificadas a partir dos significados atribuídos ao conceito? Esses são assuntos que devem ser deixados para uma outra oportunidade.

Por fim, pretendemos ter contribuído também para ressaltar o importante papel que o conceito de Spanish America teve na consolidação da doutrina do Destino Manifesto. Mesmo que alguns traços desse sentimento de superioridade excepcional tenham surgido já nas primeiras décadas de existência dos EUA, ele somente se consolidou através, ou melhor, em oposição àquilo que os americanos percebiam como Spanish America. Com a ascensão do poderio americano no século XX, Spanish America ou Latin America deixaram de ter exclusividade como antípoda da auto-imagem nacional americana. No século XXI, com o grande aumento da imigração hispânica e, em especial, mexicana, a nação americana voltou a confrontar a "ameaça" da convivência com os hispânicos. ${ }^{22}$ Resta-nos saber se a solução agora apontará para a aceitação e incorporação ou para a segregação e rejeição do Outro que vem do sul.

JOÃO FERES JÚNIOR é professor associado do Instituto Universitário de Pesquisas do Rio de Janeiro (Iuperj).

\section{REFERÊNCIAS BIBLIOGRÁFICAS}

ADAMS, John Quincy, and Charles Francis Adams. (1970). Memoirs of John Quincy Adams: comprising portions of his diary from 1795 to 1848.1 st AMS edition, ed. New York: AMS Press.

AGASSIZ, Louis, and Elizabeth Cabot Cary Agassiz. (1895). A Journey in Brazil. Boston.

ALLMAN, T. D. (1984). Unmanifest Destiny; Mayhem and Illusion in American Foreign Policy; From the Monroe Doctrine to Reagan's War in El Salvador. Garden City: Doubleday.

ARDAO, Arturo (1980). Genesis de la idea y el nombre de America Latina. Caracas, Venezuela: Centro de Estudios Latinoamericanos Romulo Gallegos.

ARISTOTLE (1958). The Politics of Aristotle. Translated by Ernest Barker. New York: Oxford University Press.

BEBDER, S (2003). Greasers and gringos : Latinos, law, and the American imagination. New York: New York University Press.

BERRIEN, John (1847). Congressional Globe, Appendix, 5 February, 301.

BEVERIDGE, Albert (1900). Congressional Record, 9 January, 711.

BUSH, George W. (2003). State of the Union: President's State of the Union Message to Congress and the Nation. New York Times, January 29, 12.

CALLHOUN, John (1848). Congressional Globe, 4 January, 96-99.

CAMARILlO, A. (1990). Chicanos in California : a history of Mexican Americans in California. Sparks: Materials For Today's Learning.

CAPPON, Lester J., ed. (1988). The Adams-Jefferson Letters: The Complete Correspondence between Thomas Jefferson and Abigail and John Quincy Adams. Chapel Hill: University of North Carolina.

CODMAN, John (1867). Ten Months in Brazil, with Incidents of Voyages and Travels, Descriptions of Scenery and Characters, Notices of Commerce and Productions, etc. Boston.

CONDORCET, Marie-Jean-Antoine-Nicolas de Caritat, marquis de. (1795)(1988). Esquisse d'un tableau historique des progrès de l'esprit humain / Fragment sur l'Atlantide. Paris: Flammarion.

FABIAN, Johannes (1983). Time and the other; how anthropology makes its subject. New York: Columbia University Press. FERES Jr., J. (2003). “The history of counterconcepts: 'Latin America' as an example.' History of Concepts Bulletin(6). GIBSON, Charles (1971). The black legend; anti-Spanish attitudes in the Old World and the New. New York: Knopf.

HAMPSHER-MONK, Iain (1998). Speech Acts, Languages or Conceptual History?, edited by I. Hampsher-Monk, K. Tilmans and F. v. Vree. Amsterdam: Amsterdam University Press. 
HORSMAN, Reginald (1981). Race and Manifest Destiny; The Origins of American Racial Anglo-Saxonism. Cambridge: Cambridge University Press.

HUNT, Washington (1847). Congressional Globe, Appendix, 13 February, 363.

HUNTINGTONn, S. P. (2004). Who Are We: The Challenges to America's National Identity. New York, Simon \& Schuster.

James Petras, H. Michael Erisman and Charles Mills (1973). The Monroe Doctrine and US Hegemony in Latin America. In Latin America: From Dependence to Revolution, edited by J. Petras. New York: Wiley.

JEFFERSON, Thomas, and Paul Leicester Ford (1904). The works of Thomas Jefferson. New York, London,: G.P. Putnam's sons.

KOSELLECK, Reinhart (1985a). Futures past; on the semantics of historical time. Cambridge and London: The MIT Press.

KOSELLECK, Reinhart (1985b). The historical-political semantics of asymmetric counterconcepts. In Futures past; on the semantics of historical time. Cambridge and London: The MIT Press.

KOSELLECK, Reinhart, Otto Brunner, and Werner Conze, (eds.) (1972-1997). Geschichtliche Grundbegriffe, 9 vols. Stuttgart: Klett-Cotta.

MALTBY, William S. (1971). The Black Legend in England; the development of anti-Spanish sentiment, 1558-1660. Durham: Duke University Press.

PAGDEN, Anthony (1982). The fall of natural man: the American Indian and the origins of comparative ethnology. Cambridge, New York: Cambridge University Press.

PARK, James William (1995). Latin American Underdevelopment; a history of perspectives in the United States, 1870-1965. Baton Rouge and London: Louisiana State University Press.

PHELAN, John Leddy (1968). Pan-latinism, French intervention in Mexico (1861-1867) and the genesis of the idea of Latin America. In Conciencia y autenticidad historicas; escritos en homenaje a Edmundo O'Gorman, edited by J. A. O. y. Medina. Mexico: UNAM.

PIKE, Frederick B. (1992). The United States and Latin America; myths and stereotypes of civilization and nature. Austin: University of Texas Press.

POWELL, Philip Wayne (1971). Tree of hate; propaganda and prejudices affecting United States relations with the Hispanic world. New York and London: Basic Books.

RICHTER, Melvin 1995. The history of political and social concepts: a critical introduction. New York; Oxford: Oxford University Press.

RICHTER, Melvin (1996). Appreciating a contemporary classic; Geschichtliche Grundbegriffe and future scholarship. In The meaning of historical terms and concepts: new studies on Begriffgeschichte, edited by H. Lehmann and M. Richter. Washington D.C.: German Historical Institute.

RICHTER, Melvin, and Hartmut Lehmann, eds. (1996). The meaning of historical terms and concepts: new studies on Begriffgeschichte. Vol. 15. Washington D.C.: German Historical Institute.

SCHOULTZ, Lars (1998). Beneath the United States: a history of US policy toward Latin America. London and Cambridge: Harvard University Press.

SCOTT, Alexander (1812). Alexander Scott to James Monroe, 16 November 1812 and 1 January (1813). In Consular Letters from La Guaira: NA M84/R1.

SIMPSON, John, and Michael Profitt (eds) (1997). Oxford English Dictionary, Additions Series. Oxford: Clarendon Press.

SMITH, Peter H. (1996). Talons of the eagle : dynamics of U.S.-Latin American relations. first ed. New York: Oxford University Press.

SQUIER, Ephraim George (1855). Notes on Central America, Particularly the States of Honduras and San Salvador. New York.

STEPHANSON, Anders (1995). Manifest destiny; American expansionism and the empire of right. New York: Hill and Wang.

TAYLOR, Robert J., and Mark Friedlaender, (eds.) (1981). Diary of John Quincy Adams. Cambridge: Belknap Press.

TORRES DE CAICEDO José Maria (1856). Las Dos Americas. In Genesis de la idea y el nombre de America Latina. Caracas, Venezuela: Centro de Estudios Latinoamericanos Romulo Gallegos.

UPSHUR, Abel (1843). Upshur to Edward Everett, 28 September 1843. In Instructions to Great Britain: NA M77/R74.

VARGAS, Antonio José Rivadeneira (1989). El bogotano J.M. Torres Caicedo (1830-1889), Lecturas de Bogotá. Bogotá: Academia Colombiana de Historia.

WATTS (1828). Watts to Clay, 10 March 1828. In Despatches from Colombia: NA T33/R4.

WILLIAMS, Appleman (1980). Empire as a Way of Life; An Essay on the Causes and Character of America's Present Predicament along with a Few Thoughts about an Alternative. New York: Oxford University Press.

' A história do aparecimento desse termo no contexto da França do segundo império é, em si, um tópico muito promissor. Para uma introdução sobre o tema, ver Phelan (1968)

${ }^{2} \mathrm{O}$ dicionário registra a primeira incidência do termo em um documento de 1890 , intitulado Reciprocity Treaties with Latin America e cuja autoria é atribuída ao presidente americano Benjamin Harrison (Simpson and Profitt 1997). Essa observação é corroborada por minha própria pesquisa. A procura pela expressão "Latin America" no 19th Century Masterfile, um dos mais completos bancos de textos publicados nos EUA e Grã-Bretanha no período (que inclui, entre outros, o Poole's Index to Victorian Periodicals) deu resultado nulo para datas anteriores a 1890. As primeiras aparições de "Latin America" registradas naquela fonte datam de 1892,1894 e 1898.

${ }^{3}$ Para uma versão um pouco mais detalhada desse estudo ver Feres Jr. (2003).

${ }^{4}$ Para uma explanação mais elaborada desse esquema análitico ver Feres Jr. "Contribuição a uma Tipologia das Formas de Desrespeito: Para Além do Modelo Hegeliano-Republicano.” Dados - Revista de Ciências Sociais 45, no. 4 (2002): 555-675.

${ }^{5}$ Para uma análise aprofundada da contribução de Koselleck à Geschichtliche Grundbegriffe ver Richter (1995; 1996; 1996) e Hampsher-Monk (1998)

${ }^{6}$ Ver o capítulo intitulado "The historical-political semantics of asymmetric counterconcepts" em Futures past; on the semantics of historical time (Koselleck 1985a).

${ }^{7}$ A análise mais completa e detalhada da Legenda Negra foi feita por Philip Wayne Powell em Tree of Hate: Propaganda and Prejudices Affecting United States Relations with the Hispanic World (1971). O estudo de William S. Maltby, The Black Legend in England:; the Development of Anti-Spanish Sentiment, 1558-1660 (1971), trata da origem e desenvolvimento desse 
mito na Inglaterra. Para uma compilação de textos originais de autores europeus célebres com alusões a Legenda Negra ver The Black Legend; Anti-Spanish Attitudes in the Old World and the New (1971), de Charles Gibson.

${ }^{8}$ Um dos topos da literatura da Legenda Negra é a afirmação de que os espanhóis trucidaram 20 milhões de índios, estimativa feita originalmente pelo padre Las Casas e que, junto com suas obras denunciando a conquista espanhola, foi recebida de braços abertos pela propaganda anti-espanhola promovida por ingleses, holandeses, alemães e franceses. Sobre esse assunto, ver Powell (1971).

9 O mais correto seria dizer "colônias ibéricas", pois, como veremos mais adiante, o Brasil não escapou dessa pecha.

${ }^{10}$ Para uma leitura crítica da recepção histórica da Doutrina Monroe ver Allman (1984) e Petras (1973).

${ }^{11}$ A palavra birthright e mongrel são de difícil tradução. A primeira diz respeito àquilo que adquirimos ao nascer, ou seja, o senador refere-se aqui aos privilégios adquiridos por uma pessoa ao nascer sob o governo dos EUA. O segundo termo, mongrel, traduz-se por mestiço, mas carrega conotações negativas, um tanto eugênicas, de mistura mal proporcionada e de degeneração física e moral - conotações essas que o termo mestiço hoje em dia parece ter perdido em grande parte. Em suma, mongrel é sempre pejorativo, enquanto que seu correlato no português brasileiro nem sempre o é.

${ }^{12}$ A redundância aliterante na tradução tenta reproduzir o original em inglês, medley of mixed races, e deve ser lida, junto com a frase anterior, como um recurso retórico de ênfase.

${ }^{13}$ Calhoun foi figura proeminente no cenário político americano da primeira metade do século XIX, ocupando os postos de deputado, secretário da Guerra, vice-presidente (1825-32), secretário de Estado, e, finalmente, senador. Representante das elites do sul dos EUA, Calhoun trabalhou arduamente pela manutenção da escravidão e o respeito aos direitos dos estados em relação aos da União.

${ }^{14}$ Mixed tribes no original, que tem o sentido literal de raças mescladas, misturadas.

${ }^{15}$ Colored races, no original.

${ }^{16}$ Emerson foi ensaísta, pastor, poeta, filósosfo e um dos principais expoentes do "trascendentalismo da Nova Inglaterra", um movimento cultural fortemente influenciado pelo romantismo europeu (Allen 1981).

${ }^{17}$ Citado por Stephanson (1995)

${ }^{18}$ Stephanson, ibid.

${ }^{19}$ Como podemos ver, o termo "selvagem” pode carregar conotações assimétricas culturais e/ou temporais. O selvagem é o incivilizado, mas também pode ser o primitivo.

${ }^{20}$ Com o passar do tempo, o Destino Manifesto transformou-se na base de sustentação ideológica do excepcionalismo americano, e passou a sevir como chave para se interpretar a posição dos EUA em relação a qualquer outro país ou povo do mundo, vide o papel que essa doutrina desempenhou na Guerra Fria e nos eventos mais recentes que sucederam o 11 de setembro. Só estamos chamando a atenção aqui para o papel importante que a representação dos mexicanos e hispanoamericanos teve no momento de sua consolidação.

${ }^{21}$ O leitor encontrará uma gama variada dessas referências em Pike (1992), e em Park (1995).

${ }_{22}$ O termo "ameaça" foi utilizado por Huntington (2004) para se referir ao assunto em artigo que se tornou célebre. 